\title{
Guiomar do Porto o leer sin perder el hilo
}

\author{
Manuel Calderón Calderón \\ Centro de Estudos de Teatro da Faculdade de Letras (Universidad de Lisboa) \\ Instituto Español de Lisboa
}

\section{RESUMEN}

El Auto de Guiomar do Porto hay que situarlo en la encrucijada del auto renacentista y las continuaciones de la Tragicomedia de Fernando de Rojas. Mi análisis parte del concepto de 'representación', entendido de tres maneras distintas. En un primer sentido teatral, señalo las semejanzas y diferencias del auto portugués con las imitaciones y continuaciones de La Celestina. Desde el punto de vista de la historia de la lectura, destaco la influecia que la lectura tiene en la conducta de la protagonista. Y desde un punto de vista iconográfico, relaciono algunos pasajes del auto con la iconosfera celestinesca y la cultura visual de la época.

Palabras Clave: Auto de Guiomar do Porto. Celestina. Teatro portugués del siglo XVI. Iconografía.

\section{Guiomar do Porto or reading without losing the thread}

\section{ABSTRACT}

The Auto de Guiomar do Porto must be placed at crossroads of the Renaissance Auto and the sequels of the Tragicomedy of Fernando de Rojas. My analysis is based on the concept of 'representation', understood in three different ways. In a first theatrical sense, I will point out the similarities and differences between the Portuguese Auto and the imitations and sequels of La Celestina. From the point of view of the history of reading, I will highlight the influence that reading has on the protagonist's behaviour. And from an iconographic perspective, I will relate some passages of the Auto to the celestinesque iconsphere and visual culture at the time.

Key words: Auto de Guiomar do Porto. Celestina. Portuguese Theatre 16th Century. Iconography. 


\section{Celestinesca 43 (2019): 33-58}

Conocemos en España una serie de piezas dramáticas, de la primera mitad del siglo XVI, que intentan trasvasar la comedia humanística al teatro representable, partiendo de la materia amorosa con tintes celestinescos y final feliz (Canet 1991; Puerto Moro 2013 y 2014). La crítica ha denominado a estas obras de distintas maneras: "romantic comedy» (Crawford 1922), "comedia urbana» (Canet 1991) y "comedia celestinesca» o "naharresca» (Puerto Moro 2016), pues son imitaciones y no continuaciones de la Tragicomedia de Fernando de Rojas. ${ }^{1}$ No obstante, La Celestina se convirtió enseguida en un modelo dramático con una poética propia, lo que propició un ciclo teatral específicamente celestinesco (Baranda, 2017). ${ }^{2}$

En el teatro portugués de la época, la alcahueta es un personaje habitual y familiar del teatro de Gil Vicente; ${ }^{3}$ y fuera de él lo encontramos en el Auto da Bela Menina, de Sebastião Pires; en las comedias de Jorge Ferreira de Vasconcelos y, a diferencia de los textos anteriores, en el anónimo Auto de Guiomar do Porto (Camões 2007: 219-258), pues aquí lo hace ya dentro de una trama típicamente celestinesca. Dada su singularidad, trataré de situar este auto en el contexto del teatro peninsular celestinesco y, señaladamente, en relación con las continuaciones de la Tragicomedia de Fernando de Rojas. Empecemos por su argumento.

\section{[Primera escena] (vv. 1-110)}

Guiomar, una joven de quince años y medio, es presa del mal de amores. Al despertar a su mozo Rodrigo y declarar que quiere labrar sus penas en una almohada, él le dice que estaba soñando con ella y, a continuación, le entrega una almohaza para la "comichão». "Se foras doudo ['botarate' o 'majadero'], Rodrigo, / eu te castigara já; / mas parvo ['bobo', 'simple'] não tem castigo».

\section{[Segunda escena] (vv. 111-271)}

Entran el Namorado con su mozo Gregório y una Alcoviteira, quien recibe seis cruzados y un anillo por llevar de su parte una trova a Guiomar.

1.- Me refiero a la Égloga de Calisto y Melibea (1513), de Pedro Manuel de Urrea; la Himenea (1517), de Torres Naharro; la Comedia Ypólita (1521); Radiana (c. 1525-1535), de Agustín Ortiz; Vidriana y Tesorina (c. 1528-1535), de Jaime de Huete; Tidea (impresa en 1550, pero c. 1530), de Francisco de las Natas; Grassandora (1540 ad quem), de Juan Uceda de Sepúlveda y Rosabella (1550, aunque probablemente anterior), de Martín de Santander.

2.- Forman este ciclo la Penitencia de amor (1514), de Pedro Manuel Jiménez de Urrea; la Segunda Celestina (1534), de Feliciano de Silva; la Tercera Celestina (1539), de Gaspar Gómez de Toledo; la Lisandro y Roselia (1542), de Sancho de Muñón; la Tragedia Policiana (1547), de Sebastián Fernández; la Comedia Selvagia (1554), de Alonso de Villegas y la Tragicomedia de Polidoro y Casandrina (1564 a quo).

3.- Aparece en el Auto do Velho a horta, Auto da Barca do Inferno, Comédia de Rubena, Farsa de Inês Pereira, Auto dos Físicos, Farsa do Juiz da Beira y Romagem dos Agravados.

4.- Cuando Elicia protesta de que Celestina no la deja tener amores con el paje del infante, también recurre a la almohaza: «al diablo la vieja clueca [...] que con esta almohaça te tengo de almohaçar» (Segunda Celestina, XXXIX Cena). 
[Tercera escena] (vv. 272-311)

Gregório previene a su amo como Pármeno hiciera con Calisto, igualmente sin éxito. "Se o bom com mal sucede, / ao certo seu louvor tem", concluye Gregório.

[Cuarta escena] (vv. 312-530)

La Alcoviteira llega a casa de Guiomar haciéndose pasar por una ropavejera. Oposición entre el árbol seco y el florido, más tópico del carpe diem. Rodrigo discanta sobre el diálogo entre la alcahueta y Guiomar. Antes de despedirse, la Alcoviteira se asegura la colaboración de Rodrigo dándole un real y despertando su apetito (sexual) al prometerle un pastel («comer» y "carne» forman parte del mismo campo simbólico que «bordar» $\mathrm{y}$ «tejer», como es habitual en el teatro celestinesco).

[Quinta escena] (vv. 531-560)

Soliloquio de Guiomar al leer la trova que le ha dejado la alcahueta.

[Sexta escena] (vv. 561-689)

Consejos del Padre de Guiomar. Rodrigo trata de mulo al Padre por su ceguera ante los tejemanejes de la niña con la celestina, resumidos en la cantiga final de esta escena, al tiempo que juega con el doble sentido de «capuz».

[Séptima escena] (vv. 690-768)

Guiomar, a solas, desprecia los consejos paternos. Riñe a Rodrigo por denunciar a su padre las visitas de la alcahueta. A lo que el mozo responde que los «tolos nunca mentem» $y$ "são como cegos raivosos [como el ciego Cupido, vv. 710-714] / porque nam vem mas sentem / e dão golpes furiosos" (vv. 700-704). Tan excitado está Rodrigo, que se postula como amante ("Tens de mi bom pão caseiro, / podes-me comer de graça»).

[Octava escena] (vv. 769-818)

La alcahueta da cuenta al escudero Namorado de su recado. El hilo del diálogo es la dilogía entre "contar» las nuevas de Guiomar y «contar» el dinero que va a costar su tercería.

[Novena escena] (vv. 819-930)

La Alcoviteira llega a casa de Guiomar y lo primero que hace es entregar el pastel a Rodrigo, quien, al recibirlo, canta un villancico zejelesco donde «bolo» rima con «tolo». Guiomar decide «echar la soga tras el caldero", entregándose a los designios de la alcahueta, por consejo de la cual se escapa de casa llevándose el oro y dinero del padre. Rodrigo, renuente al principio, acaba justificando su complicidad: «roubemos quem mais puder, / como fazem em casa del rei».

[Décima escena] (vv. 931-941)

Gregório reprocha a su amo haber confiado en la alcahueta sin nada a cambio. 
[Undécima escena] (vv. 941-1014)

La Alcoviteira se presenta con el Namorado en casa de Guiomar, quien antes de desvalijar a su padre, echa la culpa al Amor hipócritamente. Rodrigo parte con la vieja y los amantes mientras entona el villancico final: "fartar-se-á o escudeiro / e a moça perder-se-á. / A mim tanto se me dá, / pois ela perdida vai. / Mal por ela e por seu pai.»

\section{Representación de lo celestinesco}

La primera característica común entre el Auto de Guiomar do Porto y las comedias urbanas de temática celestinesca es su contexto urbano. Lo sugieren la desenvoltura y densidad - para un auto- del discurso femenino, las referencias críticas a la política de consejeros y cortesanos y la cultura letrada, tanto de la alcahueta como de Guiomar.

También coinciden en la retórica cortesana que guía a los amantes, tanto en boca de Guiomar (vv. 1-20), quien conoce el Cancionero castellano y la literatura sentimental y caballeresca (vv. 441-457), como del Enamorado (vv. 111-115, 231-242, 769-778).

Otro rasgo común es la caracterización de la alcahueta. La típica buhonera es, en el auto portugués, una chamarilera o ropavejera (adela). En la primera escena, la adolescente Guiomar aparece labrando su mal de amores en una almohada (almofada). Y a lo largo del auto, el tópico del hilado y el simbolismo sexual de labrar o bordar se amplifican mediante una paronomasia (la almofaça a la que Rodrigo atribuye un uso venéreo) y una serie de dilogías (porta, comer, bolo, pão, lebre, capuz) con sus derivados.

La Alcoviteira es, además, lasciva, taimada y codiciosa. Rodrigo, el criado de Guiomar, despierta la salacidad de la vieja: «tais cordeiros quem mos desse, / juro-vos que os comesse / [...] / quant'a para tal cabrito, / nam hei eu mister cutelo» (vv. 264-271). ${ }^{5} \mathrm{Y}$ enseguida se gana la voluntad del mozo, dándole un real y con la ambigua promesa de satisfacer su lujuria. Cuando el Enamorado llama a la Alcoviteira «pastora», ella replica que "o pastor guarda o gado, / de lã dele se mantém» (vv. 161-162). Cumple la doble función de alcahueta y correveidile (llevando a Guiomar una trova de su Enamorado), pero su habilidad persuasiva va más allá de la apelación al carpe diem, envuelta en falsa modestia ("vós sois sábia e eu peca, / vós vindes e eu sou ida», vv. 355-356):

Alcoviteira Deseja quem tal deseja desgostos e enfermidade, pobreza, nojo e peleja. Filha, antes que tal seja,

5.- Así lo expresa Claudina en la Tragedia Policiana, XVI: «mala Pascua me dé Dios si debaxo de la çeniza no tengo escondida la brasa». 
lograi-vos da mocidade. (vv. 362-366)

Enquanto querem a vós, filha, logremo-nos deles; que despois quereis vós e não vos quererão eles.

Entam, tecer o retrós. (vv. 436-440)

Su codicia no se satisface con los seis cruzados que obtiene del Enamorado por su mediación, sino que juega con la anfibología de "contar» las cuentas del rosario, "contar» las nuevas de la niña y «contar» el dinero que va a ganar por la tercería:

$\begin{array}{ll}\text { NAmORADO } & \text { Por contas vindes rezando? } \\ & \text { Conta tem as que contais? } \\ & \text { As que eu estou contando } \\ & \text { terem conto é por demais. } \\ & \text { Que novas me dais de mi? } \\ & {[\ldots]}\end{array}$

Hasta el punto de que, en su segunda visita, induce a Guiomar a comportarse como una pícara o rufián celestinesco, desvalijando a sus padres. ${ }^{6}$

Pero el Auto de Guiomar do Porto se distancia en otros aspectos tanto de las comedias representables de corte celestinesco como de las continuaciones de La Celestina. Para empezar, no hay monólogo del Enamorado, pues la joven protagonista no es inaccesible ni se hace de rogar, sino

6.- Cuando Eufrosina confiesa su amor por Zelotipo, tiene reparos en entregarse a él, porque «darei má velhice a meu pai, que me quer tanto». Mas luego se pregunta —como Melibea en La Celestina, X, quien en el XVI no quiere ser malcasada- ¿por qué los hombres pueden ir en busca de sus deseos y no nosotras? "Os homens requerem o que cobiçam, tudo lhes é dado. Nós encobrimos os desejos e desejamos os que nos mais tolhem. Per fim hei de obedecer a quem todos obedecem. Se me culparem, companheiras, acharei: melhor é errar com os muitos que acertar com os poucos. Sempre o ouvi: vontade é vida. $\bigcirc$ casamento por riquezas faz haver no mundo tantas mal casadas!» (Jorge Ferreira de Vasconcelos, Comédia Eufrosina IV, 3). 
al contrario. Quien se queja de mal de amores al comienzo del auto es Guiomar y es ella quien lleva siempre la iniciativa.?

Tampoco aparecen tipos cómicos secundarios (pastores, negros, vizcaínos, gitanos, etc.), como en Vidriana, Tesorina, Rosabella, la Segunda Celestina y su Tercera parte, ni el desenlace es trágico (como en Lisandro y Roselia, Policiana y Polidoro y Casandrina) ni acaba a gusto de todos, como en la farsa picaresco-celestinesca Salamantina (1552), de Bartolomé Palau; sino que resulta en desengaño y escarmiento para el padre, mientras que para los demás personajes es un final puramente hedonista y hasta cínico.

El papel burlón, sermoneador y voyerista de los criados presenta dos novedades: la burla se hace extensiva al padre de la joven y en lugar de criada, Guiomar tiene un sirviente que pasa del voyerismo a proponer a su señora que satisfaga el prurito sexual con él y no con alguien ajeno al entorno doméstico.

En relación con lo anterior, los criados no duplican la acción principal, sino que, aparte de glosarla, Rodrigo invade el terreno de los señores poniéndose al mismo nivel que Guiomar. Bien es verdad que ella lo tiene por «tolo» $y$ "parvo" (bobo, falto de entendimiento), que es como la sensata e ingeniosa Poncia y su ama consideran a sus respectivos galanes, en la Segunda Celestina; términos cuyas fronteras semánticas son difusas en el teatro portugués del siglo XVI.

En el vicentino Auto da Fama, este personaje alegórico llama "tolo» al «parvo Joane». En el Auto da Bela Menina, de Sebastião Pires, Pasibula, el Negro y la protagonista también llaman «tolo» al "parvo». En el Auto de São Vicente, de Afonso Álvares, aparece "um pastor tolo per nome Gonçalo»; e Isabel Vaz usa este apelativo como sinónimo de 'tosco, ignorante' con el villano Pero Casco (v. 386), igual que Gil en la Comédia da Pastora Alfea (I), v. 2082, de Simão Machado. Pero en la Comédia Floresta d'Enganos, vv. 219-222, de Gil Vicente, significa 'insensato, botarate', que es lo que Guiomar parece designar con «doudo»:

$$
\begin{array}{ll}
\text { MERCADOR } & \text { Ora, enfim, } \\
& \text { quero ser tolo sandeu } \\
& \text { e só por vos socorrer, } \\
& \text { quanto mos quereis vender? }
\end{array}
$$

Este tipo aparece asociado, en el teatro de António Prestes, a la paremiología (Auto dos Dous Irmãos, vv. 1138-1142) o bien es un personaje folclórico:

Marquesa Ora três val, meu cebolo, meu marmanjo, chocalheiro,

7.- Iniciativa que en la Selvagia y en Polidoro y Casandrina se expresa de otra manera: a quienes ofrece sus hechizos la alcahueta es a las mujeres protagonistas (Isabela en un caso, Casandrina en otro), no a Selvago y Polidoro. 
meu basbaque, meu João Tolo

e meu sem nenhum miolo, meu madraço de sequeiro.

(Auto dos Cantarinhos, vv. 306-310)

Con el mismo apelativo folclórico de "Juan» se refiere Sigeril a su amo cuando lo ve escribir la carta de amor a Polandria. Y ésta y Poncia llaman a sus respectivos galanes «babusán» y «majadero» (Segunda Celestina X y XIV).

Jorge Ferreira de Vasconcelos usa el adjetivo «tolo» con el sentido de 'incauto' (Comédia Aulegrafia, ff. 21v y en la Comédia Eufrosina, ff. 70r, 131r, 132v). En la misma Aulegrafia, f. 84r, Dinardo recurre a la paronomasia "com vossos pós de latim fazeis rosto a tolo, digo Túlio" para contraponer el 'gárrulo' al elocuente; y Dinardo y Artur califican de «tolo» ('desatinado') al mundo (ff. 86r y 158r).

El mismo término aparece asociado al adulterio en el Auto das Regateiras, de António Ribeiro Chiado:

\begin{tabular}{ll} 
VelHa & Que o marido \\
& não no queria eu sabido. \\
Comadre & E pois como? \\
VelHa & \multicolumn{1}{c}{ Rico e tolo; } \\
& $\begin{array}{l}\text { que visse a corna c'o olho } \\
\text { e perguntasse: qu'é 'quilo? (f. } 4 \mathrm{~b})\end{array}$
\end{tabular}

Y en la Comédia Eufrosina, f. 92r: «ele de torto em través, muito focenhudo, com o focinho no chão: "não pode ser qu'eu sempre seja tolo, sobre cornos cinco soldos"».

En cambio, el tipo del bobo (parvo, tolo) del Auto de Guiomar do Porto es una mezcla de loco de amor ferino y de morio, bufón o loco-atrevido (Bataillon 1978: 337-338), al que se le otorga el derecho a "decir la verdad» con impunidad, a fin de que pueda desvelar la realidad que se esconde bajo convenciones sociales como la honra.

Lo cual nos lleva a otra consideración sobre el lugar común en que Rodrigo aparece durmiendo, al principio del Auto de Guiomar do Porto. En el primer auto de la Tercera parte de Celestina, de Gaspar Gómez, Felides se despierta creyendo que haber gozado sexualmente de Polandria es sólo un «sueño tan suave para mi contemplación y de tanto descanso para mi atribulado coraçón»; pero, en realidad, era el recuerdo de algo que había consumado con ella la noche anterior. El de Selvago, en cambio, era apenas un sueño (Selvagia III, 1). Mientras que el de Rodrigo es la manifestación de un deseo de realización improbable, aunque apenas reprimido, puesto que no se recata de exponerlo (mediante una elocuente gestualidad implícita) ante la propia Guiomar:

Rodrigo Sonhava que me chamava ũa moça pera um jogo 
de folgar, eu bem folgava;

e tu chamaste-me logo, eu cuidei que não sonhava. (vv. 41-45)

Recordemos, por otra parte, que una de las características cómicas del bobo es la modorra o somnolencia, asociada en los temperamentos flemáticos a la necedad (Huarte de San Juan 1991: cap. 2):
JOANE
Eu sonhava que era tolo, polo céu de Deos sonhava!
Olhai, entam eu chorava.
FAMA
Oh, Jesu como és cebolo!
(Gil Vicente, Auto da Fama, vv. 105-108) ${ }^{8}$

En relación con la serie de continuaciones propiamente dichas de la Tragicomedia de Calisto y Melibea, el Auto de Guiomar do Porto guarda algunas semejanzas significativas, como la correspondencia entre estatuto social del personaje y forma de tratamiento, que en algunas continuaciones de La Celestina se manifiesta en el abandono del tuteo humanístico. Una acepción de personas que se da también en el Auto de Guiomar do Porto, a diferencia de lo que ocurría en el teatro de Gil Vicente. Así, Guiomar emplea el pronombre tónico de tercera persona («ele») como forma de tratamiento para interpelar a la segunda («vós»):

$$
\begin{array}{ll}
\text { PAI } & \text { Filha, Deos vos dê prazer. } \\
\text { Guiomar } & \text { E a ele boa velhice. (vv. 561-562) }
\end{array}
$$

Por lo demás, las relaciones entre amos y criados discurren sin conflictos ni resentimientos, si bien no deja de traslucirse el despego de unos respecto de los intereses de otros.

A diferencia de Calisto, Felides, Lisandro, Policiano, Flerinardo y Polidoro, el Escudero de Guiomar do Porto es un desheredado. Por eso Guiomar reniega de él y de sus trovas, siguiendo el parecer de la alcahueta de Lisandro y Roselia III, 3, quien después de constatar que «doncellas de alta guisa no sólo amaron a sus amigos y servidores, mas muchas los siguieron hasta sus tierras», como hará la misma Guiomar, advierte: "jallá a las que con sus negros y esclavos y mozos de espuelas trataron sus abominables amores les venga la infamia que merecen!».

Como ocurre en otras obras del ciclo celestinesco, el Auto de Guiomar do Porto incorpora recursos y géneros extradramáticos. En lo cual es continua-

8.- Como en la Lisandro y Roselia II, 3 donde «la pájara [Roselia] volaba por el cielo con contemplaciones de Dios» hasta que Celestina la atrapa en «las imaginaciones de la carne». Oligides despierta a su amo, Lisandro, cuando soñaba con Roselia; «mas - le advierte a manera de prolepsis- no se te vuelva el sueño del perro", es decir, "no se te descomponga el logro que tienes por seguro' al haber desdeñado la realidad (IV, 1).

9.- Algo habitual en el teatro de António Prestes y documentado en otros autos del siglo xVI (Camões 2008: 11-12). 
dora de La Penitencia de amor, de Pedro Manuel Jiménez de Urrea, primera imitación de la Tragicomedia donde se combinan la ficción sentimental (la misma que dicen haber frecuentado la Alcoviteira y Guiomar) y la materia celestinesca. Asimismo, en la Tercera parte de Celestina XVIII, Felides pide a Ervión, su escudero, «un libro de leales amadores» para sobrellevar su pena, aunque probablemente se esté refiriendo al tratado de Ovidio.

Jiménez de Urrea intercala cartas (como la trova que el Enamorado envía a Guiomar y que él recita y luego ella lee y comenta en voz alta) y los protagonistas exhiben una cultura letrada y popular, como la de la Alcoviteira y Guiomar. La fosilizada retórica trovadoresca de los protagonistas sirve en ambas obras para enmascarar el apetito sexual y, por tanto, la ceguera tanto de amos como de criados.

Pero si la imitación de Urrea comparte la crítica estamental del modelo, la crítica del Auto de Guiomar do Porto es más bien política, pues en su papel de «bobo que nunca miente», lo que Rodrigo denuncia es la corrupción de la corte:

GUIOMAR Faze como vês fazer: se roubar, rouba também.

Rodrigo Mas, bofás, que dizes bem! Roubemos quem mais puder, como fazem em casa del rei! (vv. 926-930)

Con todo, la intención didáctica de Penitencia de amor, expresada en forma de sentencias e imágenes, gira en torno a la misma ceguera pasional y moral que comparten Rodrigo, Guiomar y su padre.

Así como la Segunda Celestina, de Feliciano de Silva, rechaza explícitamente el uso de la magia, evita la intervención de criados en la tercería y habla con un lenguaje bíblico, poniéndose piel de oveja para entrar en casa de la noble Polandria, la Alcoviteira de Guiomar do Porto es a la vez «pastora» del Enamorado (vv. 159-160) y «raposa» que sigue el rastro de la presa en compañía de aquél: ella misma es un «lobo» (vv. 684-685) como el lujurioso Rodrigo, de quien Guiomar se guarda: «eu cuidei que era cordeiro / e ele tornou-se lobo» (vv. 761-782). ${ }^{10}$

Al estilo de las celestinas de Feliciano de Silva y Sancho de Muñón, con sus pujos de predicadoras, ${ }^{11}$ la del auto portugués se apoya en el Salmo

10.- La misma imagen se encuentra en el teatro de Gil Vicente (Auto da Cananeia, v. 430; Breve Sumário da História de Deos, vv. 717-720; Auto da Geração Humana, 5d); en el Auto do Duque de Florença, vv.1151-1154; en el Auto da Ciosa, vv. 1391-1395 y Auto do Desembargador, vv. 1141-1153, de Antonio Prestes; y en la Comédia Ulissipo I, 1 y Comédia Aulegrafia V, 1, de Jorge Ferreira de Vasconcelos.

11.- «Muy santa está la puta vieja conmigo», refunfuña Pandulfo en la Segunda Celestina XIII. Y la alcahueta pide a Roselia que la deje acabar de rezar el rosario, porque "primero nos conviene buscar el reino de los cielos y después entender en estas cosas momentáneas cuanto baste a la necesidad de aquesta miserable vida» (Lisandro y Roselia II, 2). 
39: 6 para inducir a Guiomar a desvalijar a su padre, "pois que ajunta o rico / e não sabe pera quem» (vv. 969-970). Y tanto aquéllas como ésta instigan a la joven a seguir su determinación, ya sea mediante el matrimonio secreto, ya mediante la fuga con su amante.

En cuanto al desenlace, la decisión de Guiomar no es insólita. Zelotipo y Cariofilo también se divierten a costa del dinero de sus padres, en la Comédia Eufrosina, de Jorge Ferreira de Vasconcelos. Y la hedonista Guiomar probablemente acaba pensando, como Polandria, que «más vale un poco de pan con gozo que la casa llena de riquezas con descontentamiento. Créeme que no hay estado mayor que el del contentamiento" (Segunda Celestina XXVI).

\section{Representaciones de la lectura}

Una particularidad de Guiomar do Porto es el papel que la cultura libresca juega en la obra. En las comedias de Jiménez de Urrea y Feliciano de Silva, o bien se combinan las materias sentimental y de tercería o bien se rechaza la magia; y en la Lisandro y Roselia hay alusiones a ambas cosas: Lisandro dice hallarse "preso en cárcel de amor» (I, 1) y Eubulo rechaza la explicación del hechizo, porque "no hay otro tan eficaz hechizo como el amor» (ibidem I, 3); o como dice la celestina Elicia, glosando el tópico del Amor omnia vincit, «esta comezón de la carne es red barredora que pesca a los hombres y mujeres de cualquier estado y condición. Y esa corona o laureola ${ }^{12}$ de las vírgenes ¿qué piensas que es sino un gozo accidental?» (ibidem III, 3).

No obstante, la Alcoviteira de Guiomar do Porto hace algo más con la literatura: trata de enviscar a Guiomar apelando a su placer por la lectura:

\begin{tabular}{|c|c|}
\hline AlcoviteirA & $\begin{array}{l}\text { Nam sois devota de ler } \\
\text { cantigas, cartas d'amores, } \\
\text { livros de bons amadores? }\end{array}$ \\
\hline GUIOMAR & $\begin{array}{l}\text { Alguns tenho em meu poder } \\
\text { de mui famosos autores. }\end{array}$ \\
\hline LCOVITEIRA & $\begin{array}{l}\text { Muito gosto eu, senhora, } \\
\text { de Amadis, Cárcel d'Amor, } \\
\text { um Sermão do mesmo autor } \\
\text { e a Donzela Teodora, } \\
\text { e mais Silvestre e Amador. }{ }^{13} \\
\text { E dos autos: Aquilano, }\end{array}$ \\
\hline
\end{tabular}

12.- Es el nombre de la protagonista de la Cárcel de Amor, de Diego de San Pedro. Y el «loco desvariado» Policiano ve por primera vez a Filomena "en la huerta de los cipreses» junto a un «laurel» (Tragedia Policiana X).

13.- Las Trovas de dous Pastores (1536), de Bernardim Ribeiro. 


$\begin{array}{ll} & \text { Dom Duardos com suas flores } \\ & \text { e a Tormenta d'Amores. }{ }^{14} \\ & \text { E o Cancioneiro castelhano, }{ }^{15} \\ \text { e Boscão com seus primores. }{ }^{16} \\ \text { GUIOMAR } & \text { Todos esses tenho eu } \\ & \text { e outros que não nomeais. (vv. 441-457) }\end{array}$

Lo cual nos lleva a preguntarnos, como Julián Marías (1955: 75-78) se preguntaba en relación con la literatura de cualquier época, cómo se utilizaba un texto literario; para quién se escribía (pensemos en la novela cortesana); qué porcentaje de entre los lectores-oyentes posibles de cada género literario o de ciertas obras representativas eran mujeres; ${ }^{17}$ qué se proponía en cada caso la obra literaria y cómo se construía el sentido (Chartier 1996: 107-108). Y a propósido de las lecturas de Guiomar do Porto, cuál era el peso e influencia de la literatura en la vida, así como la distancia entre una y otra, es decir, los grados de autenticidad, sinceridad, espontaneidad y originalidad de la primera; la relación de los autores y lectores con otros textos antiguos y modernos, así como la función o sentido de esa relación.

Son cuestiones demasiado amplias para ser tratadas aquí, pero que guardan relación con las siguientes observaciones acerca del papel que desempeña la lectura en el Auto de Guiomar do Porto.

La práctica de la lectura de Guiomar está en las antípodas de la de Filomena, quien recuerda a su padre "los libros que dende mi niñez, por la nobleza del exercicio literal, me has mandado leer» y con los cuales estaba segura de oponer las armas de la discreción y la razón a los peligros de la ociosidad. Hasta que su propia vida los desmiente. ${ }^{18}$

Tanto el Amadís leído por Guiomar y la Alcoviteira como La Celestina propiciaron sendos ciclos literarios (y una tragicomedia de Gil Vicente), cuyas obras se irían alejando del sentido y la forma de sus modelos, al igual que la continuación de la Cárcel de Amor, escrita por Nicolás Núñez. Esta incorporación de temas, personajes y sociolectos, así como la conta-

14.- El Infierno de Amor, de Garci Sánchez de Badajoz, donde se encuentra Macías, el trovador gallego convertido en el enamorado por antonomasia, con quien Sigeril compara a su amo en la Tercera parte de Celestina II.

15.- El Cancionero General (1511), recopilado por Hernán del Castillo.

16.- Las Obras de Boscán y algunas de Garcilaso de la Vega (1543), de la que se imprimió una edición contrahecha en Lisboa el mismo año.

17.- Chevalier (1976: 82-83) señala como un hito de la cultura del Renacimiento la incorporación de la mujer a la lectura.

18.- A Teofilón, padre de Filomena, sólo lo vemos con un devocionario; pero los criados, rufianes y hortelanos juran por Plácida y Vitoriano, por «la ley del cuaderno» y por «la corónica de Olmedo» (Tragedia Policiana X, XV, XXVI); y Escalión, «por el terrible baladro de Merlín» y «la metafísica de Aristótiles» (Selvagia I, 1 y 2). 
minación con otros géneros, garantizaron su éxito. ${ }^{19} \mathrm{El}$ propio desenlace de Guiomar do Porto tiene un aire picaresco, como el de Polidoro y Casandrina cuando la protagonista huye con las ganancias y con su madre (que es al mismo tiempo alcahueta), una vez satisfecho el deseo carnal de la joven.

Ahora bien, la forma de auto impide, en Guiomar do Porto, las amplificaciones que permite la forma comedia. De la pareja ejemplar y única en la obra de Rojas, pasamos en la de Silva a la multiplicidad y variaciones amorosas de once parejas, que barajan el amor convencional de Quincia, el pastoril de Filínides, el cancioneril de Felides y el prostibulario de $\mathrm{Pa}$ lana. Pero aunque éste y Sigeril se mofen de las «filosofías y retóricas» de su amo, Polandria sólo se enamora después de haberlas leído, igual que le pasa a Guiomar con la cantiga de su anónimo galán.

La retórica tanto de ésta como de Felides se construye a partir de un mismo estereotipo cancioneril con sus antítesis, repeticiones, derivaciones y anástrofes:

Si pensáis con acabarme que tengo assí de acabar, pues yo no puedo engañarme os quiero desengañar, que no's queráis engañar si pensáis que me matáis, porque más vida me dais.

(Segunda Celestina XII)

Sem guia neste mar guio pois que guio mar por ti Guiomar guia tu a mim que de ti sem mim confio.

(Guiomar do Porto, vv. 231-234)

Sin embargo, Guiomar utiliza la literatura, la relaciona con su vida y construye el sentido de lo que lee sin perder el hilo que también teje la Alcoviteira con quien comparte lecturas. Tanto es así que entre sus libros destacan esos otros que no se nombran y a los que se referirá después, porque llegan a sustituir a la persona de la alcahueta: «en alguns livros que li / parceiras posso achar» (vv. 556-557).

Cuando Pandulfo intenta disuadir a Felides para que no recurra a Celestina, le dice:

Poco sabes de achaque de trama [fingir una cosa y hacer otra]; pues la mejor trama que ella puede tramar es con hiproquesía y santidad urdir para texer sus telas, que con

19.- Según el bachiller Alonso Martínez, "no se tenía por contento el que no tenía en su casa cuatro o cinco Celestinas» (Gallardo 1863-1969: III, 641). 
este hilado podrá ella mejor urdir tu tela con Polandria que el de las madexas texó el de Calisto y Melibea. (Segunda Celestina X)

Asimismo, cuando se dirige a casa de Filomena, la alcahueta Claudina dice que va "a dar la primera puntada en una labor trabajosa" (Tragedia Policiana XI). En cambio, cuando Guiomar enumera los útiles de la costura (vv. 86-130), pone esta actividad en relación con la literatura amorosa:

$\begin{array}{ll}\text { Guiomar } & \text { Vós, agulha que ensinais } \\ & \text { a linha com que coseis, } \\ & \text { a mim para que deixais, } \\ & \text { que ensinada me achareis } \\ & \text { no amor cada vez mais? (vv. 101-105) } \\ & {[\ldots]} \\ \text { Alcoviteira } & \text { Nunca vimos querer bem } \\ & \text { as damas aos servidores } \\ & \text { e eles a elas também } \\ & \text { mandarem cartas d'amores? } \\ & \text { Ũas vão e outras vem. (vv. 426-430) }\end{array}$

Ya desde el principio Guiomar quiere bordar sus penas, ${ }^{20}$ al tiempo que juega con la dilogía de pena: 'pluma' del cojín o almofada, 'pasión' y 'pluma' para escribir; pues a la inversa de la Segunda Celestina IX y XX, quien vuelve del infierno declarando que "más letras aprendí que tenía» o que alude a su experiencia echándole en cara a Poncia que "poco has leído donde yo", aquí la propia lectura es alcahueta. Algo muy próximo a lo que Roger Chartier llama "representación», donde lo real sería aquello que el texto mismo plantea como real al constituirlo en un referente fuera de sí mismo. ${ }^{21}$

En el mismo sentido, Elicia, la sobrina y continuadora de Celestina, adoctrina así a su también sobrina y pupila Drionea para que aprenda a ejercer con provecho "el sagrado evangelio date et dabitur vobis»:

¿No miraste la alhaja de atavíos y la rima que tenía llena de decretos y Baldos y de Scotos y Avicenas y otros libros? Llévoos yo allá para que deprendáis y toméis avisos y doctrinas. [...] ¿Piensas que estas del oficio que te he contado ganan a hilar o coser o labrar? [...] ¡A la he,

20.- Motivo que se encuentra en la fábula de Progne y Filomela y sus reelaboraciones (como el romance de Blancaflor y Filomena), donde ésta denuncia su violación y mutilación mediante el bordado.

21.- Por «representación» entiende Chartier (1996: 40-59) la ausencia del referente y la pressencia de un tercer término que no es lo que representa ni lo representado (unidos por una relación simbólica), sino la exhibición de una presencia nueva o sustitución. 
engañada vives si eso piensas! Vuelve la hoja, malvada perversa, haz libro nuevo. (Lisandro y Roselia I, 4)

Al contrario de los beatos Pandulfo y Eubulo, el segundo de los cuales incluye entre sus diez remedios para el mal de amores la lección devota de la Sagrada Escritura (Segunda Celestina XXX y Lisandro y Roselia IV, 4), Guiomar lee participando emocionalmente en lo que lee y esa experiencia lectora - como la de la música y el canto en los casos de Polandria y Poncia- le permite conocerse a sí misma y buscar la satisfaccción de sus necesidades a lo largo del auto; lo cual expresa Polandria, sirviéndose de los tópicos del locus amoenus y ut pictura poesis, cuando asiste con su criada a la serenata que Felides le dedica en el jardín, a la luz de la luna:

¡Oh, válame Dios, qué suavidad de boz y qué garganta!
Y con el son del ruido de las ondas del mar y el regozijo
delicado de los aires en los cipreses, como él dize, no
parece sino cosa divina, con aquel traer el aire a ondas
la boz haziendo cerca y lexos della, como en pintura de
gran artífice. (Segunda Celestina XXXI)

Esta Segunda Celestina XXIX cuenta que la negra Texeira, una antigua pupila suya, se había citado con el buldero de la Trinidad cuando los sorprendió el rufián Fragoso; facecia parecida a otras dos de Lisandro y Roselia: la primera, representada, donde es un capellán el sorprendido por Oligides cuando está con Drionea (III, 2) y la segunda, narrada por Elicia, sobre lo que pasó con el confesor de Celestina, cuyo desenlace escatológico, presencia de narrador-testigo, adecuación a la situación y al tono coloquial de los personajes coinciden con los del cuentecillo de Feliciano de Silva (Lisandro y Roselia IV, 3). ${ }^{22}$

A su vez, los cuentecillos folclóricos, interpolados tanto en la Comedia Thebayda como en las del ciclo celestinesco, sirven en las obras de Feliciano de Silva y Sancho de Muñón para crear verosimilitud. Pero este último autor va más allá y corrige al primero, pues a su juicio, contravino dicha norma al resucitar a Celestina.

Bien es cierto que, a diferencia de Juan del Enzina con su resurrección de Plácida, Feliciano de Silva lo hace cervantinamente, desmintiendo una acción ficticia (la muerte de la alcahueta de Rojas) con otra «real» (la imago veritatis de la comedia de Silva, quien descubre a la alcahueta escondida en casa del arcediano después de haberse fingido muerta con sus hechizos). Pero Sancho de Muñón aclara, por boca de Oligides, que Elicia - la "tercera Celestina», pues la de Gómez de Toledo es la misma persona que la de Feliciano de Silva - es la verdadera segunda Celestina, por ser la sobrina y heredera en el oficio de la barbuda de Fernando de Rojas, y

22.- El propio Oligides — criado de Lisandro - cita otra facecia de Poggio Bracciolini, a propósito de las baladronadas de Brumandilón (Lisandro y Roselia III, 5). 
no la ficticia Segunda Celestina de Feliciano de Silva, la cual se había hecho pasar por la resucitada de la Tragicomedia de Calisto y Melibea siendo, en realidad, "otra que tomó el apellido de su comadre». Y añade: «lo demás son ficciones» (Lisandro y Roselia I, 3).

En el mismo sentido, Elicia llega a sentirse tan aventajada sucesora de Celestina que pondera su habilidad para "abatir a la pájara» (vencer la honestidad de Roselia), comparándose con una larga serie de aves de cetrería, a la que añade otra de aves canoras para cantar su alegría y una tercera de instrumentos musicales para «resonar por el aire mi verdadera mentira» (Lisandro y Roselia II, 3).

Pero al autor del Auto de Guiomar do Porto no parece preocuparle tanto la verosimilitud de la ficción como la realidad. Rodrigo, el bobo salaz y somnoliento de Guiomar do Porto sabe - porque lo dice en el villancico final- que Guiomar se perderá, pero a él le trae sin cuidado; se limita a dejar constancia de que así es la vida (la ciceroniana imitatio vitae).

En segundo lugar, esta preocupación por lo real es más que un simple recurso para involucrar a los espectadores en la representación, como el empleado por el villano Zancada en el Aucto del rey Nabucodonosor cuando se hizo adorar, donde el bobo es el único personaje lúcido o cuerdo que se dirige al Legado del rey, hablándole de una serie de personas de su entorno cotidiano - su tío, su hermano Aguilar, su cuñada, Gil de las Heras, Lope Lumbreras y Benito de la Piña-, cuya simple mención sirve para traer la ficción representada al tiempo y espacio del espectador (Rouanet 1901: 243-244). El anacronismo sirve para crear la misma ilusión en el Misteri del rey Herodes, donde las mujeres que llevan a sus hijos menores de dos años ante Herodes el Grande son las de los pueblos de los alrededores de Valencia que han ido a la capital para presenciar la procesión del Corpus; una tradición teatral que, por cierto, incluye una manifestación de la locura festiva: la degollación de los Inocentes (García Lorenzo 1988: 288-289).

Por el contrario, lo que Rodrigo y Guiomar representan con su sentido de la realidad es más bien una inversión de valores, semejante a la de la Segunda Celestina, cuya protagonista ha "resucitado" para reclamar el ejercicio de su actividad en un mundo hedonista, jovial e intrascendente que la echaba de menos, lejos ya de la visión conflictiva y del tono sombrío de Fernando de Rojas. Asimismo, Guiomar decide seguir su instinto y no las normas del Padre; es decir, lo que Pandulfo llama en la comedia de Silva «mi filosofía natural» por oposición a las «filosofías y retóricas» de aquel San Juan de Patmos con que Sigeril identifica a su amo (Segunda Celestina X).

Hasta aquí he puesto en relación el Auto de Guiomar do Porto con las comedias representables de corte celestinesco y, sobre todo, con las pertenecientes al ciclo de obras continuadoras de La Celestina. También he señalado cómo la Alcoviteira se sirve del prestigio de la lectura para atraer a Guiomar a su terreno, aprovechándose de la vigencia de ciertas lecturas 
que conforman tanto la manera de estar en el mundo como sus decisiones a lo largo del auto. Concluiré refiriéndome al motivo de la muchacha ventanera y al tema de la ceguera amorosa, presentes en el Auto de Guiomar do Porto. Para lo cual utilizo el concepto de 'representación' no ya en el sentido hermenéutico de la historia de la lectura ni espectacular del teatro, sino iconográfico, en referencia a "las imágenes que las palabras de un texto sugieren» (Machado 2005: 14-15).

\section{Imágenes representadas}

Guiomar es una muchacha extrovertida:

GUIOMAR Grão trabalho é encobrir

e descanso é falar.

Grão pena sinto em calar

quem deseja descobrir

o que quer dissimular.

Não tem mal quem mostra o mal

e inda do mesmo bem

não no tem o que o tem

se o tem sem o mostrar

que lho não sabe ninguém. (vv. 1-10)

Y ventanera:

PAI Não cureis de ser garrida nem vos ponhais à janela.

A molher que é recolhida virtudes vivem com ela, amiga da honesta vida. (vv. 583-587)

En lo cual no se diferencia de las jóvenes del Auto de Rodrigo e Mendo, de Jorge Pinto; de las del Auto de dom André, vv. 91-92 y de las del teatro celestinesco, en general..$^{23}$

23.- Poncia y Polandria, asomadas a la ventana, hablan de sus respectivos enamorados viéndolos pasar o bien platican con ellos desde ese lugar, bien definido en la escenografía de los patios de comedias; Elicia, desde su ventana, ve a Albacín que pasa por su puerta y charlan antes de que él suba para retozar juntos (Tercera parte de Celestina, XXIV, XXV, XLVI). Lisandro se enamora de Roselia cuando la ve "recostada en la ventana del encerado» como piedra imán y, asomada a las de la torre, dice que lo recibirá (Lisandro y Roselia, I,1 y II, 2). Teofilón reprocha a Florinarda no haber vigilado la honra de su hija, "conoscido en ella ser amiga de la ventana y aun no muy enemiga de ser vista» (Tragedia Policiana, XXIII); tanto Canarín como Silvanico cantan, respectivamente, un villancico ("Levantaos por el huerto / y paraos a la ventana», Segunda Celestina IV) y una seguidilla ("Páreste a la ventana / niña en cabello, / que otro paraíso / yo no le tengo", Tragedia Policiana XXIV; Frenk 2003: 379) cuando van a preparar los encuentros amorosos de sus amos. Flerinardo, un caballero rico venido de la Nueva España, se enamora súbitamente de Rosiana cuando la ve asomada a la ventana; y a su amigo Selva- 
Se trata de un motivo iconográfico incorporado en pinturas como la Alegoría del Buen Gobierno (1338-1340), donde Ambrogio Lorenzetti incluye dos mujeres ventaneras (una encima del corro de danzantes y otra detrás de una cortina, más a la izquierda) y tres balconeras (en el extremo izquierdo del fresco); motivo que repetirá Bartolomé Esteban Murillo como tema principal del lienzo Mujeres en la ventana (1655-60) y que muy bien podría ilustrar una de las las escena citadas:

PolandRIA.- ¿¿íste lo que dixo aquel galán?

Poncia.- Señora, oílo yo y sentístelo tú.

PolandRIA.- ¡Toma, en mal punto, porque digas malicias!

Por mi vida, que me pareció tan bien que no pude

dexar de reírme, y creo, noramala para ti, que pensó que me reía con él.

Poncia.- Sea para él, señora, y para mi enamorado, que pienso, pardiós, que de mí no la puede llevar buena. Mas mira qué hablar tienen, y, pardiós, que tornan.

Felides.- Tú, Sigeril, ¿no viste cómo se me reyó mi señora?

SigeRIL.- Pardiós, señor, pues la mía no la fue en çaga. (Segunda Celestina XXIV)

Otro tema iconológico, el de la ceguera moral («mas como tal cego guia / coitado quem vai detrás» — dice Guiomar a Rodrigo, vv. 723-724), procede de la Biblia (Eclesiastés 2: 14; Lc. 6: 39 y Mt 15: 14) y se repite en el teatro y las artes plásticas del Renacimiento. ${ }^{24}$

Bien es verdad que al poderoso dios Eros-Cupido no siempre se le representa ciego, ya que en la tradición platónica hay dos tipos de amor: el de Afrodita Pandemo o amor de los sentidos (cupiditas) y el de Afrodita Urania o amor divino, espiritual o virtuoso (caritas) (Platón, Simp. 180d). De manera que el lamento de Teofilón acaba con el dictado omnia praetereunt praeter amare Deum (Tragedia Policiana, XXIX), frente a los amantes ciegos como Felides (Tercera parte de Celestina IX) y el fogoso e idealista Romeo, cuyo "amor es ciego y le conviene más la oscuridad", según Benvolio (Romeo y Julieta II, 1).

go le ocurre lo mismo con Isabela, quien más tarde lo espera "en la fenestra de su aposento» (Comedia Selvagia I, 1; II, 1; IV, 1).

24.- Auto da Geração Humana, f. 9b: «se o cego outro guia, / ambos cair nũa cova / lhe convém»; Aucto del rey Nabucodonosor cuando se hizo adorar, cuya didascalia inicial reza: "entra la Ceguedad en un carro que le tiran Fe y Razón" y cuyo villancico alude al triunfo de aquélla, instigadora de la acción de Nabuc, sobre la Fe y la Razón (Rouanet 1901: 232-251); Tragedia Policiana, en las palabras de El actor al lector. En el terreno del arte, recordemos la Parábola de los ciegos (1568), de Pieter Brueghel, el Viejo, en el Museo de Capodimonte de Nápoles. En la sillería de coro de la catedral de Zamora, obra del taller de Jan Yneres o de Bruselas, hay una escena que guarda gran similitud con la de Brueghel, según Mateo Gómez (1979). 
Aunque esta ceguera es atributo de la filosofía platónica, sólo aparece en el arte a partir del Trecento (Sebastián 1995: 152). Alonso de Ledesma (1606: 354) describe en un jeroglífico a dos Cupidos: uno con venda y otro sin ella: «entre amor casto y lascivo / esta diferencia topo, / que uno es lince y otro, topo». En Guiomar do Porto la ceguera está referida concretamente al segundo: el apetito venéreo. Y aparece caracterizada con los rasgos de la necedad en la escena en que el Padre de Guiomar pide a Rodrigo que le ayude a vestir el ropón:

$\begin{array}{ll}\text { PAI } & \text { Ergue-o e sacude-o já, } \\ & \text { quebra-me os olhos com ele. } \\ \text { RodRIGO } & \text { Arre mu! Virai-vos lá, } \\ & \text { que vos quero albardar nele. } \\ & \text { O capelo bem está. } \\ \text { PAI } & \begin{array}{l}\text { Pera diante, ratinho, } \\ \text { mo pões? Oh, cousa perdida! (vv. 658-664) }\end{array}\end{array}$

Ceguera que, otras veces, presenta los rasgos de la furia:

RODRIGO Pois os tolos nunca mentem e mais, se são maliciosos, são como cegos raivosos, porque nam vem mas sentem e dão golpes furiosos. (vv. 700-704).

Los libros sentimentales trataron de recuperar un tercer tipo de amor, codificado por la tradición cortés, cuando ya empezaba a fosilizarse y poco antes de que el teatro español y portugués del Renacimiento comenzaran a parodiarlo. De manera que sólo el amor naturalista, ferino o hereos, disfrazado con la retórica cortés, será objeto de la materia celestinesca.

Cupido se pinta ciego - declara Poncia-y con un arco en la mano para que él tire su flecha; y donde halla buen acogimiento, allí se aposenta; que como tiene la vista tapada, tanto reside en el pastor como en el ciudadano, y en el escudero como en el caballero, y en el conde como en el duque, y en el rey como en el emperador. Finalmente, este amor tiene una propriedad que, do sobra la porfía y falta la resistencia, no dexa durar la pudicicia. (Tercera parte de Celestina X).

En efecto, Cesare Ripa representa al Furor con atributos muy parecidos a los del Cupido lascivo: un joven con los ojos vendados portando un haz de azagayas (Fig. 1). 


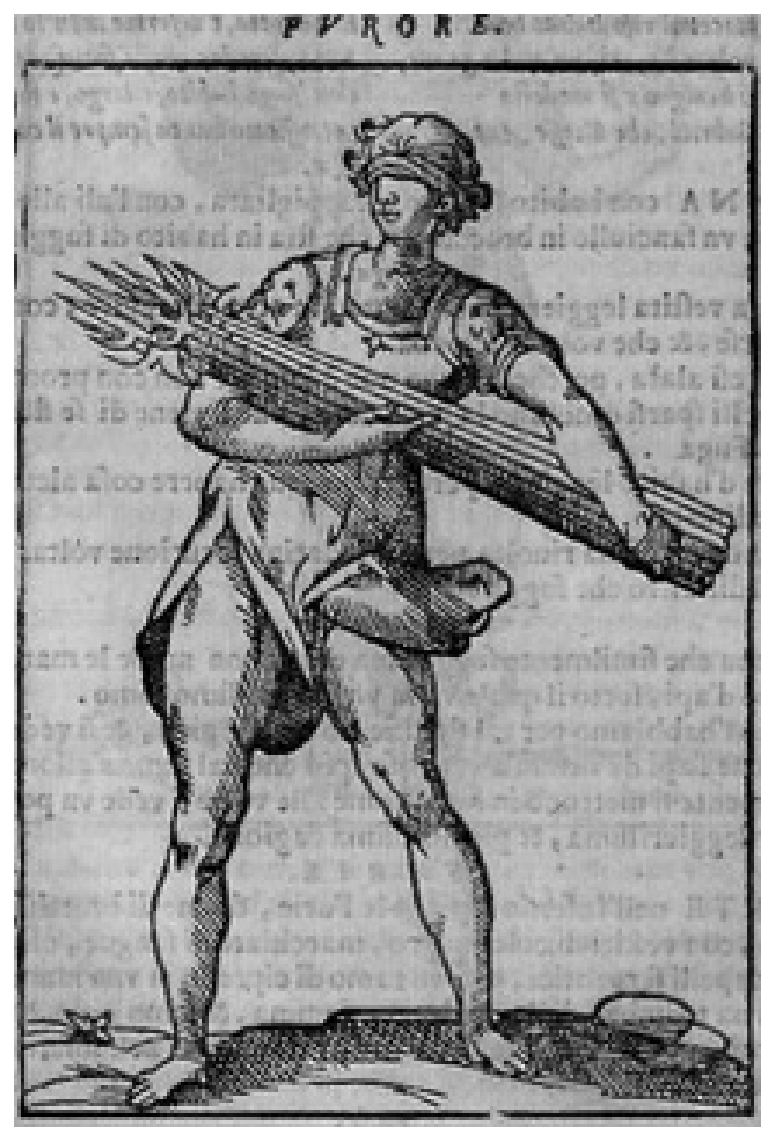

[Fig. 1]

El Furor en la Iconología de Cesare Ripa (1603)

El furor se asociaba, a su vez, a la locura ${ }^{25}$ y ésta, al amor hereos, como en el refrán que Fernando cita en el Auto Pastoril Português, vv. 348-349, de Gil Vicente, que Sancho de Muñón pone en boca de la prostituta Drionea: "amor loco, amor loco: yo por vos y vos por otro" (Lisandro y Roselia IV, 3; Frenk 2003: 751). Los criados de Policiano insisten en ello, al observar que su amo "da voces como loco", "olvidado de la razón en una especie de locura que turba el entendimiento, aparta el ingenio y priva de la memoria» (Tragedia Policiana III y VIII). Es la locura provocada por el amor concupiscente a la que se refieren el Arcipreste de Talavera o Corbacho, I, vii; el Bachiller de la Torre (Salvador Miguel 1977: 268) y el doctor Francisco López de Villalobos (Cátedra, 1989: 63-64).

25.- Difficile est stulto semper caelare furorem (Joannes Sambucus, Emblemata (1566), S. 225, apud Henkel y Schöne, 1996: col. 1824). 
Locura, sacrilegio y lujuria se combinan en la actuación de Felides, según Polandria (Segunda Celestina XIV). Mientras que en Guiomar do Porto, el bobo se expresa verbal y gestualmente de forma obscena:

RodRIGO Moça que comichão tem

há mister almofaçada.

Coçai-vos com ela bem. (vv. 71-73)

[...]

Pois ardeis como a brasa, muita água tem Rodrigo:

matemos o fogo em casa.

Eu contigo e tu comigo. (vv. 731-733)

Son los mismos elementos que encontramos en el Triunfo del Loco, del tarot de Leber (siglo XVI), personificados en un soldado armado hasta los dientes, que lleva un caracol por cerbillera o celada, camina envuelto en una nube de moscas y orina con el pene al aire. El lema al pie del dibujo reza: velim fundam dari mihi ("me gustaría que me dieran una honda»), que es una cita de Los eunucos IV, 7, de Terencio: fundam tibi nunc nimis uellem dari, ut tu illos procul hinc ex occulto caederes ("ahora sólo me gustaría que dispusieras de una honda para hacerlos trizas desde aquí, de lejos y escondido») (Fig. 2).

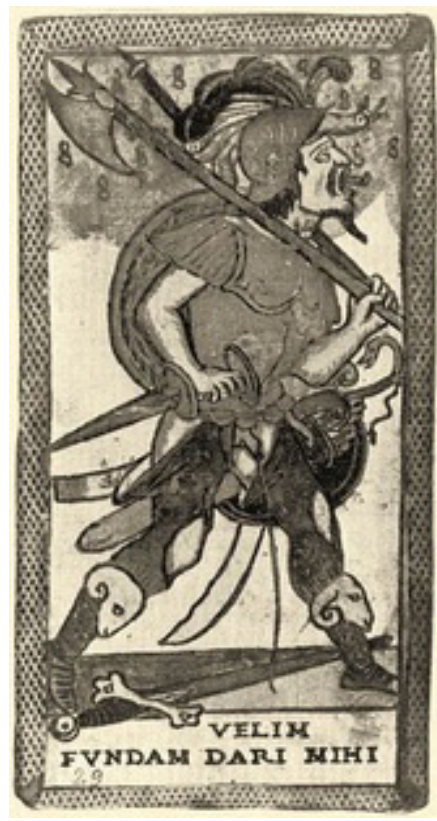

[Fig. 2]

El triunfo del Loco en el tarot de Leber, Biblioteca Municipal de Rouen (s. XVI) 
De acuerdo con el tópico del mundo al revés, la sustitución de la celada por un caracol alude a la cobardía o falso coraje humanos (Gutiérrez Baños 1997: 153-156; Pedrosa 1995: 121-132), encarnados en el soldado fanfarrón del teatro latino y en la larga lista de bravucones celestinescos (Centurio, Traso el Cojo, Pandulfo, Tripa en Brazo, Montón de Oro, Calverino, Bravonel, Brumandilón, Palermo y Pizarro, Escalión, etc.):

Y pues no la sabes -ilustra Centurio a Albacín cuando van a fornicar con Areusa y Elicia-, aprende de tal doctor como yo los misterios de la santa germanía, y de tal capitán general cómo se han de hazer los ardides de la guerra, tirando tiros mortales sin sacar sangre ni vertella, blasonando bien, digo, del arnés [es decir, 'fanfarroneando en tiempo de paz con las valentías que uno dice haber hecho en la guerra']. (Segunda Celestina XXXVI)

Fuera del mundo del hampa, Hernando de Soto expresa el carácter ciego o furioso de la cupiditas vistiendo a Cupido de guerrero. Y justifica la igualación del amante con el soldado porque ambos viven en permanente «temor, sospecha y guerra» (Soto 1599: f. 63r); lo cual confirma El actor a un amigo suyo en la Tragedia Policiana. ${ }^{26}$

En consonancia con lo anterior, el bobo y rijoso Rodrigo se dirige así a Guiomar:

Tu cuidas que não sou gente porque me vês mal vestido, pois o lutador despido peleija mais fortemente. (vv. 745-748)

Y prosigue con los tópicos de la batalla de amor (vv. 754-758), ${ }^{27}$ de la alegórica ciudad-mujer (vv. 206-210) y del asedio de Troya (vv. 191-195):

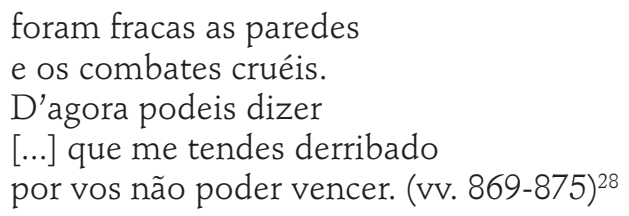

Todo el acto VI de la Tercera parte de Celestina está organizado como el asedio a una fortaleza. Felides viste cota de malla y Sigeril va provisto de

26.- La identificación del amante con el guerrero procede del amor cortés y pervive en la poesía barroca (Sebastián, 1985: 19; Manero, 1990: 77-82). «Sois um Orlando Furioso»-le dice dice Inês a Mendo en el Auto de Rodrigo e Mendo, f. 55a, de Jorge Pinto.

27.- Como en Grassandora (Gillet 1961: 54), Segunda Celestina XV, Lisandro y Roselia V y Tragedia Policiana I, IV y XXIII.

28.- En esta que Polandria llama «la cruel guerra de la sinrazón de amor» (Segunda Celestina XXXI), Calisto describe a Melibea ajustándose a la descripción de Helena hecha en la Crónica troyana (Gilman 1974: 332-333). 
espada y casco para la cita con Polandria; aunque el romance y villancico de Canarín hacen pensar a Sigeril que "no haya gran batalla para entrar en la fortaleza ganada", como Polandria da a entender: "quien la tuvo [licencia] para ganar el campo, convenible cosa le es que la tenga sin pedirla para usar de todos los tiros y artillería que en él hallare, diciendo de palabras lo que quisiere y obrando con las armas cuando tiempo le diere lugar.» Sin embargo, Poncia con sus celos "me tira tiros tan recios - se queja Sigeril- que me puso de arte que ni aprovecharan en tal caso cuantas armas hay en Milán ni broqueles en Barcelona que resistieran de no venir herido" (Tercera parte de Celestina X).

En la obra de Sebastián Fernández, Solino recomienda a su amo «poner artillería contra el muro que tan fuerte parece», porque, como dice Claudina, «más fuerte era Troya» y

el coraçón de Filomena creí yo ser de un diamante, un inexpunable castillo y un río caudal sin puente. Todo lo ha batido, todo lo tiene aportillado, todo lo ha destruido Policiano con dineros y la Claudina con conjuros. (Tragedia Policiana I, IV y XXIII).

Recordemos, por último, que en el Auto de Guiomar do Porto Rodrigo aparece dormido al principio y sólo cuando Guiomar lo despierta, su lujuria se desata; "que ansí como la mucha tristeza acarrea sueño, por el consiguiente el demasiado plazer lo evita» (Tercera parte de Celestina I). La imagen iconográfica de esta escena nos la proporciona el emblema de las flechas y el arco de Cupido rotos, que ilustran el tema de la ociosidad dañina -cuyos peligros son un lugar común en el teatro celestinesco$y$, en particular, el ocio que induce a la pasión amorosa. Más específicamente, la imagen del arco y flechas rotos suele simbolizar la derrota del Amor ferino o libidinoso («sueño de la conversación de los que mucho se aman", del cual la perspicaz Poncia quiere despertar a su ama) por el sueño del "natural» o "limpio amor» (Segunda Celestina XXXI; Martínez Pereira 2006: 109). Lo cual coincide con la interpretación del sueño de Flerinardo, en la que Selvago opone el amor del "manso unicornio» al «sucio» o «bestial» del «mono mofador» (Selvagia I, 3 y II, 3).

Sin embargo, en lugar de rechazar la "conversación" que "con vicio promete contentamiento e alcançando el fin, dexa el desengaño", como hace Dorotea en la Tragedia Policiana XXVIII cuando descubre el cadáver de Filomena («iO, amor mundano! [...] ¡Loco es quien en ti confía! [...] Tú eres ciego, pues ¿a quién puedes guiar en camino que se salve? ¡Vete, amor!»), Guiomar de Porto decide seguir la sugerencia de la alcahueta, quien le da la vuelta al Salmo 39: 6, interpretándolo según el tópico del collige, virgo, rosas. Lo que hace 
también la alcahueta de Feliciano de Silva con el Salmo 37: 21 y Mt. 25: 13, exhortando a Poncia a gozar de su juventud para «parecer un ángel». ${ }^{29}$

A través de los abundantes paralelismos y diferencias que presenta el Auto de Guiomar do Porto con el teatro celestinesco peninsular, hemos podido perfilar la originalidad de esta variante poco conocida de teatro celestinesco, relacionada con las continuaciones de la Tragicomedia de Fernando de Rojas.

La acción de Guiomar do Porto transcurre en un contexto urbano, con personajes que hacen gala de una cultura letrada y una retórica cortesana, combinadas con la acumulación de refranes y el vocabulario connotativo y simbólico, caracterísicos del género.

La figura de la alcahueta responde, igualmente, al canon celestinesco; pero Guiomar tiene un confidente varón y no una doncella. Tampoco interpola cuentos o facecias. Como en otras comedias del ciclo, Guiomar es una curiosa mezcla de tipos literarios: una joven expectante ante las urgencias del sexo, que tiene algo de pícara como los criados-rufianes de las imitaciónes de La Celestina; y a semejanza de Galterio (el criado paternal, por su tutela moral sobre Polidoro) y la Corneja (madre de Casandrina y al mismo tiempo alcahueta), en el último exponente del género: la Tragicomedia de Polidoro y Casandrina.

Aunque comparte el hedonismo de la Segunda Celestina, Guiomar do Porto se distancia tanto de la solución matrimonial, pública o secreta, iniciada por Feliciano de Silva, como del final trágico de las otras tragicomedias.

Ofrece, además, noticias sugerentes sobre la práctica de la lectura, la cual juega un papel dinámico en las motivaciones de la protagonista; hasta el punto de que llega a sustituir, en el fuero interno de Guiomar, a la propia celestina. Esta relación entre el mundo interior o psicológico de Guiomar y el mundo físico o exterior se corresponde con la relación que la obra establece entre la ficción y la realidad, trascendiendo tanto la ingenua identificación de ambos planos como la simple búsqueda de la verosimilitud.

Finalmente, el Auto de Guiomar do Porto se relaciona no sólo con la literatura, sino también con la iconosfera de las comedias celestinescas y la cultura visual de la época, a través de un motivo iconográfico (la muchacha ventanera) y de dos temas iconológicos (la ceguera moral y el amor furioso), presentes en la pintura y en la emblemática de su época.

29.- «¿Y no sabes, mal pecado, que tan presto se va el cordero como el carnero? ¿Y qué seguro tienes de Dios, mi amor, para llegar a vieja? Nunca, hija, en cuanto tengas con qué pagar, tomes fiado, porque, en fin, es más caro, y por fuerça ha de llegar el tiempo de la paga, y muchas vezes al tiempo de la paga no tenemos con qué pagar y házennos esecución por la paga, y pónennos en la cárcel hasta pagar la postrera blanca, como lo dize el Evangelio [Mt. 18: 2830]. Assí que, hija, en cuanto tuvieres con qué pagar a Dios las mercedes que te dio con darte ser y hermosura y gracia, y sobre todo hazerte cristiana, no aguardes a la vejez, pues, mi amor, no sabemos el día ni la ora de la muerte» (Segunda Celestina X). 


\section{Bibliografía}

Baranda Leturio, Consolación (2017), "Las comedias del ciclo celestinesco Segunda comedia de Celestina y Comedia Selvagia», en David Alvarez Roblin y Olivier Biaggini (ed.), La escritura inacabada. Continuaciones literarias y creación en España. Siglos XIII a XVII, Madrid, Casa de Velázquez, pp. 69-84.

Bataillon, Marcel (1978), Erasmo y el erasmismo, Barcelona, Crítica.

Camões, José (ed.) (2007), Teatro português do século XVI. Teatro profano. Tomo I, Lisboa, Imprensa Nacional-Casa da Moeda.

CANET, José Luis (1991), "La evolución de la comedia urbana hasta el Index prohibitorum de 1559», Criticón, 51, pp. 21-42.

Catalogue des livres imprimés, manuscrits, estampes, dessins et cartes à..., Bibliothèque municipale de Rouen, 1839, vol. 1.

CÁtedra, Pedro M. (1989), Amor y pedagogía en la Edad Media. (Estudios de doctrina amorosa y práctica literaria), Universidad de Salamanca, Salamanca.

CHARTIER, Roger (1996), El mundo como representación. Estudios sobre historia cultural, Madrid, Gedisa.

CheValier, Maxime (1976), Lectura y lectores en la España del siglo XVI y XVII, Madrid, Turner.

ChIADo, António Ribeiro (1994), Teatro de António Ribeiro Chiado (Autos e Práticas), ed. de Cleonice Berardinelli e Ronaldo Menegaz, Porto, Lello \& Irmão - Editores.

Fernández, Sebastián (1992), Tragedia Policiana, edición y estudio de Luis Mariano Esteban Martín, tesis doctoral dirigida por Víctor Infantes, Madrid, Universidad Complutense.

Frenk, Margit (2003), Nuevo Corpus de la Antigua Lírica Popular Hispánica (siglos XV a XVII), Méjico, Universidad Nacional Autónoma de México / El Colegio de México / Fondo de Cultura Económica, 2 vols.

Gallardo, Bartolomé J. (1863-1869), Ensayo de una biblioteca de libros raros y curiosos, Madrid, Rivadeneyra, 4 vols.

García Lorenzo, Luciano (1988), "Locos e inocentes: el Misteri del rey Herodes y la tradición teatral», Revista de Dialectología y Tradiciones Populares, XLIII, pp. 279-289.

Gillet, Joseph E. (1961), Propalladia and Other Works of Bartolomé de Torres Naharro, Bryn Mawr y Filadelfia, University of Pennsylvania Press, vol. 4 Gilman, Stephen (1974), La Celestina: arte y estructura, Madrid, Taurus.

Gómez de Toledo, Gaspar (1973), Tercera parte de la Tragicomedia de Celestina, ed., introd. y notas de Mac E. Barrick, Filadelfia, University of Pennsylvania Press. 
GutiérRez Baños, Fernando (1997), «La figuración marginal en la baja Edad Media: temas del 'mundo al revés' en la miniatura del siglo XV", Archivo español de arte, 278, pp. 143-162.

Henkel, Arthur y ScHÖnE, Albrecht (ed.) (1996), Emblemata. Handbuch zur sinnbildkunst des XVI. und XVII. Jahrhunderts, Stuttgart-Weimar, Metzler.

Huarte de San Juan, Juan (1991), Examen de ingenios para las ciencias, ed. Felisa Fresco Otero, Madrid, Espasa-Calpe.

Ledesma, Alonso de (1606), Segunda parte de los Conceptos espirituales y morales, Burgos, Cristóbal Lasso.

Machado, João Nuno Sales (2005), A imagem do teatro. Iconografia do teatro de Gil Vicente, Lisboa, Caleidoscópio / Casal de Cambra.

Mateo Gómez, Isabel (1979), Temas profanos en la escultura gótica española. Las sillerias de coro, Madrid, CSIC.

MARíAs, Julián (1955), La estructura social. Teoría y método, Madrid, Sociedad de Estudios y Publicaciones.

Manero Sorolla, Pilar (1990), Imágenes petrarquistas en la lírica española del Renacimiento. Repertorio, Barcelona, Promociones Publicaciones Universitarias.

Martínez Pereira, Ana (2006), "La representación del amor en la emblemática española de los siglos XVI y XVII», Revista de Estudos Ibéricos, 3, pp. 101-138.

Muñón, Sancho de (2009), Lisandro y Roselia, ed. de Rosa Navarro Durán, Madrid, Cátedra.

Pedrosa, José Ma (1995), Las dos sirenas y otros estudios de literatura tradicional. De la Edad Media al siglo XX, Madrid / Méjico, Siglo XXI editores.

Prestes, António (2008), Autos de..., intr. de José Camões, ed. de José Camões e Helena Reis Silva, Lisboa, Imprensa Nacional-Casa da Moeda.

Puerto Moro, Laura (2013), "En la fragua del teatro renacentista», en Teatro español de los Siglos de Oro: dramaturgos, textos, escenarios, fiestas, dir. J. M. ${ }^{a}$ Díez Borque, Madrid, Visor, pp. 22-23.

- (2014), "Tanteos en el primer teatro renacentista: la Comedia Hipólita», eHumanista, 28, pp. 611-619.

- (2016), "La comedia urbana de corte celestinesco: corpus, cronología, contextualización ritual, estructura y motivos recurrentes», Criticón, 126, pp. 53-78.

RipA, Cesare (1603), Iconología overo descrittione di diverse imagini cavate dall'antichità, el di propria inventione / trovate et dichiarate da Cesare Ripa Perugino, cavaliere de Santi Mauritio \& Lazaro; di nuovo revista \& dal medesimo ampliata di 400 \& piu imagini, Roma, apresso Lepido Facii.

RojAs, Fernando (y "antiguo autor») (2000), La Celestina, Tragicomedia de Calisto y Melibea, ed. de Francisco J. Lobera y Guillermo Serés, Paloma Díaz-Mas, Carlos Mota e Íñigo Ruiz Arzálluz, y Francisco Rico, Barcelona, Crítica.

Rouanet, Léo (ed.) (1901), Colección de Autos, Farsas y Coloquios del siglo XVI, Barcelona / Madrid, L'Avenç / Librería M. Murillo. 
Salvador Miguel, Nicasio (1977), La poesía cancioneril. El Cancionero de Estúniga, Madrid, Alhambra.

Sebastián, Santiago (1985), "Lectura crítica de la Amorum Emblemata de

Otto Vaenius", Boletín del Museo e Instituto Camón Aznar, XXI, pp. 5-512.

- (1995), Emblemática e historia del arte, Madrid, Cátedra.

Silva, Feliciano de (1988), Segunda Celestina, ed. de Consolación Baranda, Madrid, Cátedra.

Sото, Hernando de (1599), Emblemas moralizadas, Madrid, Herederos de Juan Íñiguez de Lequerica.

Teatro de Autores Portugueses do século XVI <http://www.cet-e-quinhentos. com/obras>

Tragicomedia de Polidoro y Casandrina (Ms. II-1591 de la Real Biblioteca) (2015), edición y estudio de Pedro Luis Críes Garcés, tesis dirigida por Ana Vian Herrero, Madrid, Universidad Complutense.

Vasconcelos, Jorge Ferreira de (1951), Comédia Eufrosina, ed. de Eugenio Asensio, Madrid, Consejo Superior de Investigaciones Científicas.

- (1969), Comédia Aulegrafia, ed. de António A. Machado Vilhena, Porto / Coimbra / Lisboa, Porto editora.

- (2006), Comédia Ulissipo, ed. de Rosário L. Santos, Lisboa, tesis doctoral, Lisboa, Faculdade de Ciências Sociais e Humanas, Universidade Nova.

Villegas, Alonso de (1873), Comedia Selvagia, ed. del Marqués de la Fuensanta del Valle, Madrid, Rivadeneyra (Colección de libros españoles raros o curiosos, 5). 